\title{
Analysis of Video Signal Transmission Through DWDM Network Based on a Quality Check Algorithm
}

\author{
S. Ilic \\ Dpt. of Elec. and \\ Comp. Engineering \\ University of \\ Prishtina \\ Kosovska Mitrovica, \\ Serbia \\ sinisa.ilic@ \\ pr.ac.rs
}

\author{
B. Jaksic \\ Dpt. of Elec. and \\ Comp. Engineering \\ University of \\ Prishtina \\ Kosovska Mitrovica, \\ Serbia \\ branimir.jaksic@ \\ pr.ac.rs
}

\author{
M. Petrovic \\ Dpt. of Elec. and \\ Comp. Engineering \\ University of \\ Prishtina \\ Kosovska Mitrovica, \\ Serbia \\ mile.petrovic@ \\ pr.ac.rs
}

\author{
A. Markovic \\ Dpt. of \\ Telecommunications \\ University of Nis \\ Nis, Serbia \\ acomarkovic87@ \\ yahoo.com
}

\author{
V. Elcic \\ Dpt. of Information \\ Technology \\ University of \\ Slobomir P \\ Bijeljina, Bosnia and \\ Herzegovina \\ vanja.elcic@ \\ gmail.com
}

\begin{abstract}
This paper provides an analysis of the multiplexed video signal transmission through the Dense Wavelength Division Multiplexing (DWDM) network based on a quality check algorithm, which determines where the interruption of the transmission quality starts. On the basis of this algorithm, simulations of transmission for specific values of fiber parameters are executed. The analysis of the results shows how the BER and Q-factor change depends on the length of the fiber, i.e. on the number of amplifiers, and what kind of an effect the number of multiplexed channels and the flow rate per channel have on a transmited signals. Analysis of DWDM systems is performed in the software package OptiSystem 7.0, which is designed for systems with flow rates of $2.5 \mathrm{~Gb} / \mathrm{s}$ and $10 \mathrm{~Gb} / \mathrm{s}$ per channel.
\end{abstract}

Keywords - BER parameter; $Q$ factor; DWDM network; amplifying section

\section{INTRODUCTION}

Dense Wavelength Division Multiplexing (DWDM) is a technology that allows multiplexing of multiple optical carrier signals on a single optical fiber by using different wavelengths for transmission of various information. The smallest attenuation of the signal in the optical fiber is achieved by applying the wavelength of $1550 \mathrm{~nm}$ or by using the "third optical window" [1-4].

DWDM systems allow the expansion of the existing capacity without laying additional fibers in optic cables. The capacity of the existing system is expanded using multiplexers and demultiplexers at the ends of the system [5-6].

For the successful transmission of optical signals over long distances, doped fiber amplifiers with erbium (EDFA - Erbium Doped Fiber Amplifier) are used. Erbium is a rare element and, when excited, it is emitting the light at a wavelength of 1,54 $\mu \mathrm{m}$, which is the wavelength at which the attenuation of signal power is minimal. Weak signals enters the erbium doped fiber, in which light is injected by lasers pumps. This light excites erbium atoms, and the atoms are releasing the accumulated energy in a form of additional light with wavelength around $1550 \mathrm{~nm}$. As this process continues through the fiber, the signal is amplified. EDFA is available in the $\mathrm{C}$ and $\mathrm{L}$ windows but with quite narrow range $(1530-1560 \mathrm{~nm})$ [7-8].

EDFA can amplify optical signals as much as they can be multiplexed in a given range until a strong enough signal is received. When the level of the signal at the input is reduced, the signal can not step up all multiplexed signals.

\section{BER AND Q FACTOR}

The performance of an optical communication system is specified by the Bit Error Ratio (BER) [7-8]. BER is the probability that the impulse is interpreted incorrectly (i.e. a logical ' 1 ' is detected as ' 0 ' and vice versa). Thus, a BER of $10^{-6}$ corresponds to an average of one error per million bits. The BER value depends on the characteristics of the laser source and the transmission route. With the increase of the flow in optical systems, in both systems with standard single mode optical fiber and systems with special purpose fiber, effects of spontaneous emission, polarization mode dispersion, chromatic dispersion, optical fiber nonlinearities and noise in the receiver are increasing. Therefore, BER measurement is of great importance when more adequate results are in question [7-8, 9]. The criteria used in optical receivers is that BER is less than $10^{-9}$.

For a fluctuating signal received at a decision circuit, sampling is performed at time $t_{D}$. The sampled value of the signal $I$ varies from one bit to another around the mean value $I_{1}$ or $I_{0}$, depending on whether the bit is corresponding to 1 or 
0 in the bit stream. The decision circuit compares sampled values with the threshold value $I_{D}$ and calls the bit 1 if $I>I_{D}$ or 0 if $I<I_{D}$. An error occurs if $I<I_{D}$ for bit 1 or if $I>I_{D}$ for bit 0 . Both errors can be included in the definition of error probability as [7-8]:

$$
\mathrm{BER}=p(1) P(0 / 1)+p(0) P(1 / 0)
$$

where $p(1)$ and $p(0)$ are the probability of receiving bits 1 and 0 , respectively, $P(0 / 1)$ is the probability that 0 was decided when 1 was received and $P(1 / 0)$ is the probability that 1 was decided when 0 was received. If the probability of occurrence of bits 1 and 0 are equal, then $p(1)=p(0)=1 / 2$ and BER is given by:

$$
\mathrm{BER}=\frac{1}{2}[P(0 / 1)+P(1 / 0)]
$$

BER with the optimum adjustment for decision threshold depends only on the parameter Q :

$$
\mathrm{BER}=\frac{1}{2} \operatorname{erfc}\left(\frac{\mathrm{Q}}{\sqrt{2}}\right) \approx \frac{\exp \left(-\mathrm{Q}^{2} / 2\right)}{\mathrm{Q} \sqrt{\pi}}
$$

and $\operatorname{erfc}$ is short for complementary error, defined by [10]:

$$
\operatorname{erfc}(x)=\int_{x}^{+\infty} \exp \left(-y^{2}\right) d y
$$

The parameter Q can be written as [1-2]:

$$
\mathrm{Q}=\frac{I_{0}+I_{1}}{\sigma_{0}+\sigma_{1}}
$$

where $\sigma_{1}^{2}, \sigma_{0}^{2}$ are noise variance corresponding to the symbols 1 and 0 , respectively.

An approximate form of BER is obtained by using the asymptotic expansion $\operatorname{erfc}(\mathrm{Q} / \sqrt{2})$ and is quite accurate for $\mathrm{Q}>3$.

\section{SYSTEM MODEL AND ALGORITHM}

Analysis of the DWDM transmission system was performed using the software package OptiSystem 7.0 [11]. The algorithm used for the quality check of the DWDM transmission is presented in Figure 1. The quality check algorithm applies to a fixed flow rate $\mathrm{R}$. The parameters that vary are the number of DWDM channels (8 to 512) and the length of the amplifying section AS (km), at whose ends EDFA amplifiers are placed. The parameter that is being evaluated is the $\mathrm{Q}$ factor, which shows whether the transmission quality is good. The boundary value for this factor is $Q=6$.

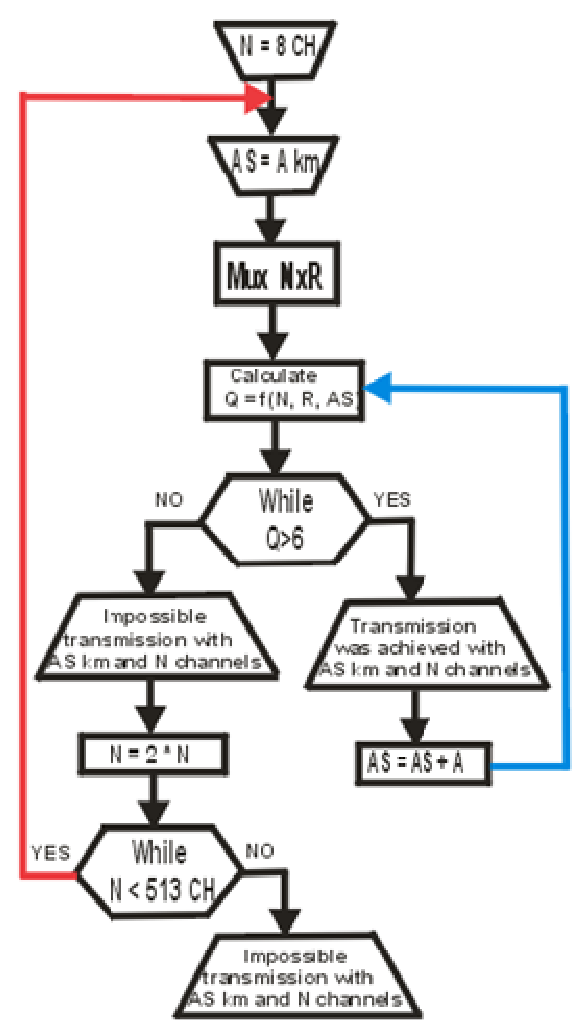

Fig. 1. Algorithm for the evaluation of quality of DWDM transmission network during the design stage.

The algorithm consists of a sub-cycle and a main cycle, for which the number of execution varies. The sub-cycle (blue line in Figure 1) refers to the number of shares and the number of its executions depends on the values of the $Q$ factor for $a$ variable number of shares and constant number of DWDM channels. The main cycle (red line in Figure 2) refers to the number of DWDM channels, contains a sub-cycle for each section and it is repeated seven times, for three values of $\mathrm{N}(\mathrm{N}$ $=8,16,32,64,128,256,512$ ).

At the beginning there are eight channels $(\mathrm{N}=8)$. After multiplexing (constant flow per channel, N DWDM channels), the signal is sent to an amplifying section AS (A km in length). The $\mathrm{Q}$ factor is calculated for the given values of $\mathrm{AS}, \mathrm{R}$ and $\mathrm{N}$. If the condition $\mathrm{Q}>6$ is met, quality transmission is achieved and then the number of shares is increased by 1 (A extra $\mathrm{km}$ ). After that, the algorithm will start from the part related to the calculation of $\mathrm{Q}$, that is the sub-cycle (blue line in Figure 1) will be repeated until the condition $\mathrm{Q}>6$ is met.

When the condition is not met, the sub-cycle is not repeated, and the current $\mathrm{N}$ and $\mathrm{AS}$ values are the values for which high-quality transmission is not possible. Once the subcycle is ended, the number of channels $\mathrm{N}$ will double and the 
algorithm is starting from the beginning, i.e., from the part that is refering to the multiplexing of the flow $\mathrm{R}$ with increased value of N DWDM channels. Again, the cycle starts from one section, the length of a A km, but for double the value of the number of DWDM channels. The previous sub-cycle will be repeated as many times as needed to achieve the required quality during the transfer. Once the sub-cycle is ended, the cycle will be repeated with double the number of DWDM channels and it will be examined whether the current value of channels is $\mathrm{N}<513$, since this is the condition for ending the main cycle.
The algorithm is applied for the specific values of the optical fiber system defined by the ITU G.652 standard [1213]. Two systems are observed, the first with a flow rate of 2.5 $\mathrm{Gb} / \mathrm{s}$, and the second with a flow rate of $10 \mathrm{~Gb} / \mathrm{s}$. The system is analyzed for 16, 32 and 64 DWDM channels, while the length of the amplifying section ranges from 40 to $80 \mathrm{~km}$. The dispersion characteristics of the fiber are given in Table I, and the diagram of the DWDM network analyzed in OptiSystem is given in Figure 2.

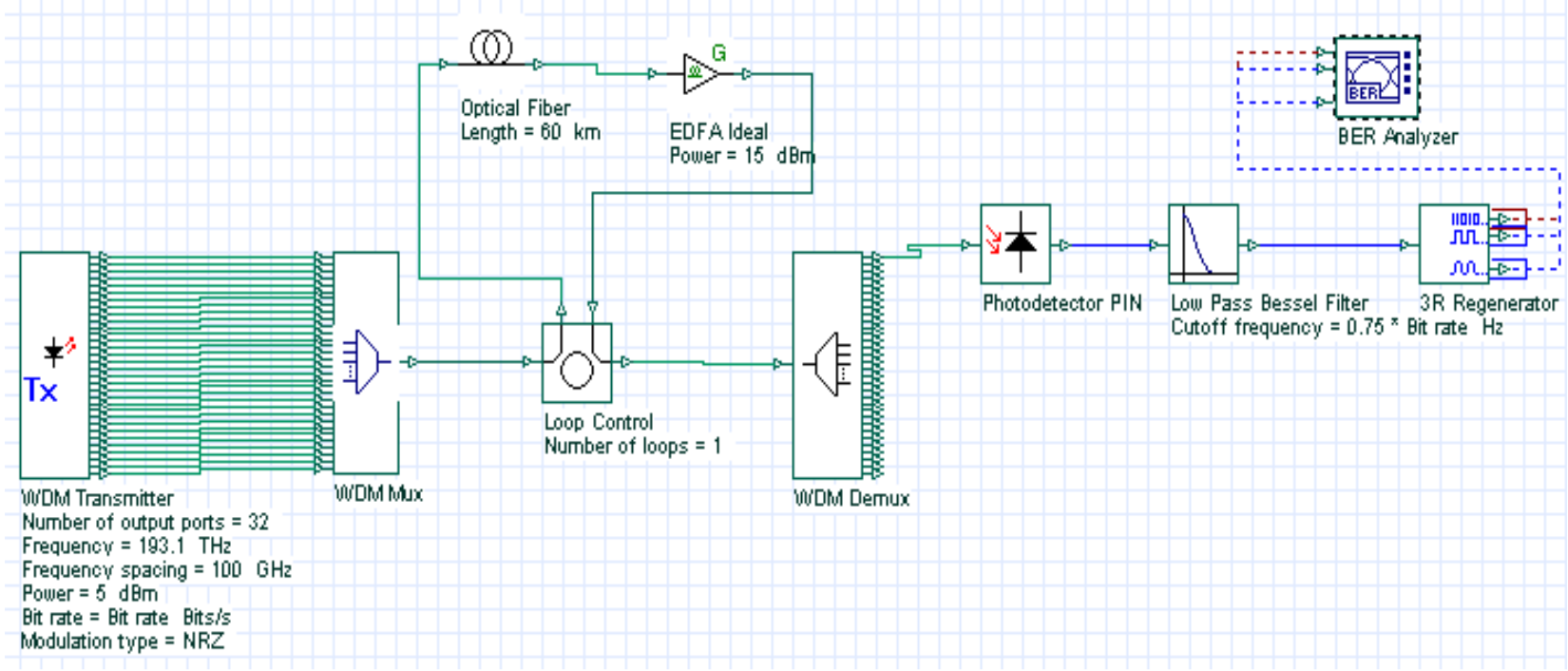

Fig. 2. 16-channels DWDM network.

Power emitted by each source is $5 \mathrm{dBm}$. After receiving the digital signals, multiplexing is performed in DWDM multiplexers. The frequency of each channel is separated by 1 $\mathrm{GHz}$. Then a multiplexed signal is sent through an optical fiber where on every A $\mathrm{km}$ a EDFA amplifier is set, with the following parameters: Gain $=20 \mathrm{~dB}$, Power $=15 \mathrm{dBm}$. Since the system works in the third optical window, the attenuation along the length of the fiber is $0.2 \mathrm{~dB} / \mathrm{km}$. On the receiving side, demultiplexing of the signals is done using DWDM demultiplexer running at the same frequency as the DWDM multiplexer.

At the receiver, a BER analyzer is set to determine the values for BER and $Q$, based on which one can determine the performance of the transmission system. Results showed that the change of BER and Q depends on the length of the fiber, i.e. on the number of the amplifying shares, and they also showed what kind of an effect the number of multiplexed channels and the flow rate per channel have on signal transmission.

\section{SimULATION RESULTS}

Table II and Table III provide the BER parameter for flow per channel at $2.5 \mathrm{~Gb} / \mathrm{s}$ and $10 \mathrm{~Gb} / \mathrm{s}$, respectively. Based on the obtained values of BER, the graphs shown in Figures 3-7 were drawn, showing that the value of the $\mathrm{Q}$ factor decreases with the change in the number of DWDM channels and the length of the amplifying section. The Purple dashed straight line represents the limit at which signal transmission quality distorts.

If the limit of the quality transmission is a BER value of $10^{-9}$ and $\mathrm{Q}=6$, when the number of DWDM channels incerases quality transmission can be achived only if the the length of the section is reduced. Decrease of the $\mathrm{Q}$ factor is much more pronounced in the first amplifying sections, while with the greater number of them, Q factor becomes approximately constant.

TABLE I. DISPERSION CHARACTERISTICS OF THE ANALYZED FIBERS

\begin{tabular}{|c|c|c|c|}
\hline Name & Value & Units & Mode \\
\hline Group velocity dispersion & Include & & Normal \\
\hline Third-order dispersion & Include & & Normal \\
\hline Dispersion data type & Constant & & Normal \\
\hline Frequency domain parame & Not include & & Normal \\
\hline Dispersion & 16.75 & $\mathrm{ps} / \mathrm{nam} / \mathrm{km}$ & Normal \\
\hline Dispersion slope & 0.075 & $\mathrm{ps} / \mathrm{nm}^{\wedge} 2 / \mathrm{km}$ & Normal \\
\hline Beta 2 & -20 & $\mathrm{ps}^{\wedge} 2 / \mathrm{km}$ & Normal \\
\hline Beta 3 & 0 & $\mathrm{ps}^{\wedge} 2 / \mathrm{km}$ & Normal \\
\hline
\end{tabular}


TABLE II. BER PARAMETER VALUES FOR THE FLOW PER CHANNEL OF 2.5 GB/S

\begin{tabular}{|c|c|c|c|c|c|c|c|c|c|c|c|}
\hline \multirow{2}{*}{ 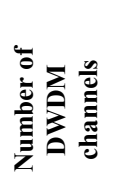 } & \multirow{2}{*}{ 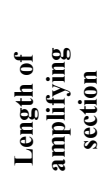 } & \multicolumn{10}{|c|}{$\begin{array}{c}\text { Number of } \\
\text { amplifying section }\end{array}$} \\
\hline & & 1 & 2 & 3 & 4 & 5 & 6 & 7 & 8 & 9 & 10 \\
\hline \multirow{5}{*}{16} & $40 \mathrm{~km}$ & $2.80 \mathrm{E}-183$ & $2.84 \mathrm{E}-087$ & $1.73 \mathrm{E}-063$ & $3.36 \mathrm{E}-055$ & $4.07 \mathrm{E}-043$ & $2.41 \mathrm{E}-039$ & $5.17 \mathrm{E}-029$ & $1.95 \mathrm{E}-023$ & $3.62 \mathrm{E}-020$ & $5.16 \mathrm{E}-020$ \\
\hline & $50 \mathrm{~km}$ & $1.18 \mathrm{E}-182$ & $2.35 \mathrm{E}-089$ & $1.32 \mathrm{E}-053$ & $1.14 \mathrm{E}-036$ & $9.29 \mathrm{E}-027$ & $7.67 \mathrm{E}-020$ & $6.60 \mathrm{E}-018$ & $2.05 \mathrm{E}-015$ & $7.41 \mathrm{E}-013$ & $3.05 \mathrm{E}-011$ \\
\hline & $60 \mathrm{~km}$ & $8.59 \mathrm{E}-174$ & $1.78 \mathrm{E}-082$ & $4.22 \mathrm{E}-056$ & $2.64 \mathrm{E}-039$ & $1.87 \mathrm{E}-035$ & $6.12 \mathrm{E}-026$ & $2.39 \mathrm{E}-019$ & $1.49 \mathrm{E}-015$ & $5.02 \mathrm{E}-014$ & $6.67 \mathrm{E}-012$ \\
\hline & $70 \mathrm{~km}$ & $8.68 \mathrm{E}-167$ & $1.89 \mathrm{E}-112$ & $4.95 \mathrm{E}-054$ & $1.45 \mathrm{E}-036$ & $9.72 \mathrm{E}-030$ & $1.46 \mathrm{E}-026$ & $1.66 \mathrm{E}-022$ & $1.97 \mathrm{E}-017$ & $3.49 \mathrm{E}-014$ & $8.96 \mathrm{E}-015$ \\
\hline & 80 km & $5.56 \mathrm{E}-166$ & $3.68 \mathrm{E}-101$ & $1.99 \mathrm{E}-063$ & $1.68 \mathrm{E}-026$ & $7.88 \mathrm{E}-011$ & 0.0014 & 1 & 1 & 1 & 1 \\
\hline \multirow{5}{*}{32} & $40 \mathrm{~km}$ & $1.17 \mathrm{E}-177$ & $5.63 \mathrm{E}-076$ & $5.28 \mathrm{E}-062$ & $7.10 \mathrm{E}-044$ & $3.13 \mathrm{E}-039$ & $6.55 \mathrm{E}-032$ & $2.76 \mathrm{E}-026$ & $2.54 \mathrm{E}-023$ & $4.82 \mathrm{E}-019$ & $8.02 \mathrm{E}-017$ \\
\hline & $50 \mathrm{~km}$ & $5.85 \mathrm{E}-160$ & $2.27 \mathrm{E}-065$ & $8.52 \mathrm{E}-047$ & $2.52 \mathrm{E}-036$ & $9.97 \mathrm{E}-025$ & $4.74 \mathrm{E}-019$ & $2.72 \mathrm{E}-016$ & $2.67 \mathrm{E}-013$ & $7.72 \mathrm{E}-012$ & $2.88 \mathrm{E}-010$ \\
\hline & $60 \mathrm{~km}$ & $5.36 \mathrm{E}-169$ & $1.64 \mathrm{E}-074$ & $1.94 \mathrm{E}-051$ & $2.82 \mathrm{E}-034$ & $6.68 \mathrm{E}-024$ & $1.66 \mathrm{E}-020$ & $3.20 \mathrm{E}-017$ & $3.24 \mathrm{E}-014$ & $1.09 \mathrm{E}-012$ & $1.51 \mathrm{E}-010$ \\
\hline & $70 \mathrm{~km}$ & $7.79 \mathrm{E}-164$ & $2.58 \mathrm{E}-068$ & $7.24 \mathrm{E}-042$ & $1.33 \mathrm{E}-029$ & $1.09 \mathrm{E}-022$ & $3.94 \mathrm{E}-020$ & $8.12 \mathrm{E}-016$ & $8.13 \mathrm{E}-014$ & $1.58 \mathrm{E}-012$ & $1.16 \mathrm{E}-010$ \\
\hline & $80 \mathrm{~km}$ & $1.78 \mathrm{E}-164$ & $3.14 \mathrm{E}-081$ & $9.84 \mathrm{E}-047$ & $1.21 \mathrm{E}-021$ & $7.66 \mathrm{E}-009$ & 0.0047 & 1 & 1 & 1 & 1 \\
\hline \multirow{5}{*}{64} & $40 \mathrm{~km}$ & $1.92 \mathrm{E}-067$ & $1.41 \mathrm{E}-048$ & $2.73 \mathrm{E}-043$ & $1.82 \mathrm{E}-030$ & $6.28 \mathrm{E}-026$ & $3.22 \mathrm{E}-023$ & $5.43 \mathrm{E}-022$ & $2.45 \mathrm{E}-018$ & $2.68 \mathrm{E}-018$ & $2.52 \mathrm{E}-016$ \\
\hline & $50 \mathrm{~km}$ & $9.73 \mathrm{E}-065$ & $1.35 \mathrm{E}-044$ & $1.55 \mathrm{E}-039$ & $4.96 \mathrm{E}-029$ & $3.15 \mathrm{E}-023$ & $1.02 \mathrm{E}-018$ & $2.31 \mathrm{E}-015$ & $3.90 \mathrm{E}-013$ & $5.85 \mathrm{E}-011$ & $3.13 \mathrm{E}-010$ \\
\hline & $60 \mathrm{~km}$ & $7.22 \mathrm{E}-065$ & $8.84 \mathrm{E}-051$ & $1.05 \mathrm{E}-043$ & $2.53 \mathrm{E}-034$ & 7.13E-024 & 3.33E-017 & $7.13 \mathrm{E}-015$ & $2.90 \mathrm{E}-013$ & $6.41 \mathrm{E}-013$ & $3.88 \mathrm{E}-010$ \\
\hline & $70 \mathrm{~km}$ & $5.19 \mathrm{E}-061$ & $2.77 \mathrm{E}-045$ & $5.63 \mathrm{E}-029$ & $1.36 \mathrm{E}-024$ & $5.17 \mathrm{E}-022$ & $2.52 \mathrm{E}-017$ & $4.53 \mathrm{E}-015$ & $8.40 \mathrm{E}-014$ & $2.12 \mathrm{E}-011$ & $2.05 \mathrm{E}-010$ \\
\hline & $80 \mathrm{~km}$ & $1.83 \mathrm{E}-061$ & $1.94 \mathrm{E}-038$ & $7.81 \mathrm{E}-024$ & $8.37 \mathrm{E}-014$ & $1.25 \mathrm{E}-008$ & 0.0051 & 1 & 1 & 1 & 1 \\
\hline
\end{tabular}

TABLE III.

BER PARAMETER VALUES FOR THE FLOW PER CHANNEL OF $10 \mathrm{~GB} / \mathrm{S}$

\begin{tabular}{|c|c|c|c|c|c|c|c|c|c|c|c|}
\hline \multirow{2}{*}{ 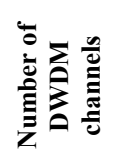 } & \multirow{2}{*}{ 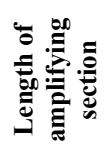 } & \multicolumn{10}{|c|}{$\begin{array}{c}\text { Number of } \\
\text { amplifying section }\end{array}$} \\
\hline & & 1 & 2 & 3 & 4 & 5 & 6 & 7 & 8 & 9 & 10 \\
\hline \multirow{5}{*}{16} & $40 \mathrm{~km}$ & $1.25 \mathrm{E}-145$ & $6.34 \mathrm{E}-069$ & $3.76 \mathrm{E}-040$ & $4.23 \mathrm{E}-028$ & $1.08 \mathrm{E}-018$ & $2.27 \mathrm{E}-013$ & 1.82E-009 & 0.0014 & 0.0024 & 0.0028 \\
\hline & $50 \mathrm{~km}$ & $3.78 \mathrm{E}-138$ & $3.18 \mathrm{E}-059$ & $9.42 \mathrm{E}-031$ & $5.51 \mathrm{E}-018$ & $1.29 \mathrm{E}-011$ & $1.18 \mathrm{E}-008$ & 0.0007 & 0.001 & 0.0017 & 0.0021 \\
\hline & $60 \mathrm{~km}$ & $6.96 \mathrm{E}-142$ & $9.46 \mathrm{E}-049$ & $6.03 \mathrm{E}-024$ & $5.67 \mathrm{E}-015$ & $7.68 \mathrm{E}-009$ & 0.0005 & 0.0009 & 0.002 & 0.0026 & 0.0034 \\
\hline & $70 \mathrm{~km}$ & $3.51 \mathrm{E}-126$ & $6.01 \mathrm{E}-055$ & $3.25 \mathrm{E}-023$ & $1.39 \mathrm{E}-010$ & 0.0005 & 0.0014 & 0.0016 & 0.0021 & 0.0028 & 0.0032 \\
\hline & $80 \mathrm{~km}$ & $1.80 \mathrm{E}-117$ & $5.72 \mathrm{E}-040$ & $1.65 \mathrm{E}-014$ & 0.0009 & 0.0018 & 0.0414 & 1 & 1 & 1 & 1 \\
\hline \multirow{5}{*}{32} & $40 \mathrm{~km}$ & $3.31 \mathrm{E}-094$ & $6.37 \mathrm{E}-066$ & $1.81 \mathrm{E}-036$ & $1.29 \mathrm{E}-026$ & $1.99 \mathrm{E}-017$ & $4.63 \mathrm{E}-013$ & $3.16 \mathrm{E}-009$ & 0.0016 & 0.0026 & 0.0031 \\
\hline & $50 \mathrm{~km}$ & $8.33 \mathrm{E}-090$ & $3.97 \mathrm{E}-048$ & $8.41 \mathrm{E}-025$ & $2.06 \mathrm{E}-016$ & $1.98 \mathrm{E}-010$ & $8.55 \mathrm{E}-008$ & 0.0009 & 0.0012 & 0.0024 & 0.0032 \\
\hline & $60 \mathrm{~km}$ & $1.25 \mathrm{E}-080$ & $2.15 \mathrm{E}-039$ & $5.70 \mathrm{E}-021$ & $1.87 \mathrm{E}-013$ & $4.01 \mathrm{E}-008$ & 0.0006 & 0.0012 & 0.0025 & 0.0037 & 0.0059 \\
\hline & $70 \mathrm{~km}$ & $2.47 \mathrm{E}-080$ & $4.65 \mathrm{E}-032$ & $8.55 \mathrm{E}-016$ & $1.54 \mathrm{E}-009$ & 0.0008 & 0.0014 & 0.0019 & 0.003 & 0.0034 & 0.0046 \\
\hline & $80 \mathrm{~km}$ & $1.31 \mathrm{E}-070$ & $1.20 \mathrm{E}-030$ & $3.97 \mathrm{E}-012$ & 0.0009 & 0.0031 & 1 & 1 & 1 & 1 & 1 \\
\hline \multirow{5}{*}{64} & $40 \mathrm{~km}$ & $5.602 \mathrm{E}-048$ & $3.31 \mathrm{E}-047$ & $2.02 \mathrm{E}-030$ & $3.29 \mathrm{E}-023$ & 4.42E-017 & $3.50 \mathrm{E}-012$ & $3.61-008$ & 0.0026 & 0.0028 & 0.0032 \\
\hline & $50 \mathrm{~km}$ & $6.32 \mathrm{E}-045$ & $2.04 \mathrm{E}-034$ & $7.28 \mathrm{E}-023$ & $6.46 \mathrm{E}-015$ & $4.73 \mathrm{E}-010$ & 0.0006 & 0.001 & 0.0012 & 0.0028 & 0.0046 \\
\hline & $60 \mathrm{~km}$ & $2.40 \mathrm{E}-044$ & $1.75 \mathrm{E}-033$ & $8.84 \mathrm{E}-019$ & $1.83 \mathrm{E}-010$ & 0.0007 & 0.0007 & 0.0012 & 0.0026 & 0.0035 & 0.0059 \\
\hline & $70 \mathrm{~km}$ & $3.26 \mathrm{E}-044$ & $1.84 \mathrm{E}-028$ & $4.34 \mathrm{E}-014$ & $4.36 \mathrm{E}-009$ & 0.0011 & 0.0015 & 0.0031 & 0.0037 & 0.0037 & 0.0044 \\
\hline & $80 \mathrm{~km}$ & $6.10 \mathrm{E}-045$ & $3.13 \mathrm{E}-020$ & $1.88 \mathrm{E}-009$ & 0.0014 & 0.0043 & 1 & 1 & 1 & 1 & 1 \\
\hline
\end{tabular}

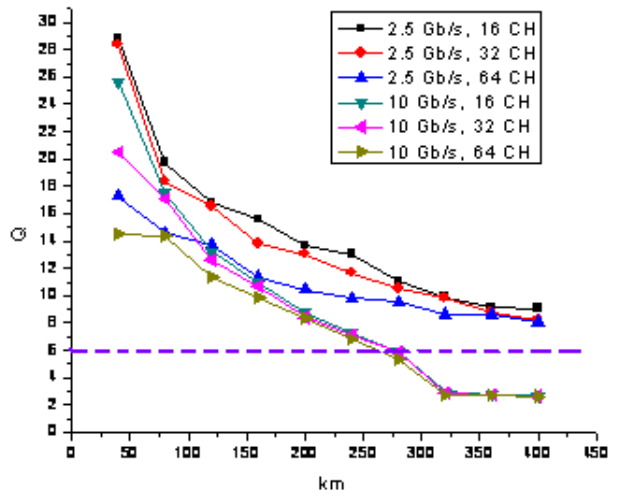

Fig. 3. Changing the $Q$ factor for length of the amplifying section $40 \mathrm{~km}$.

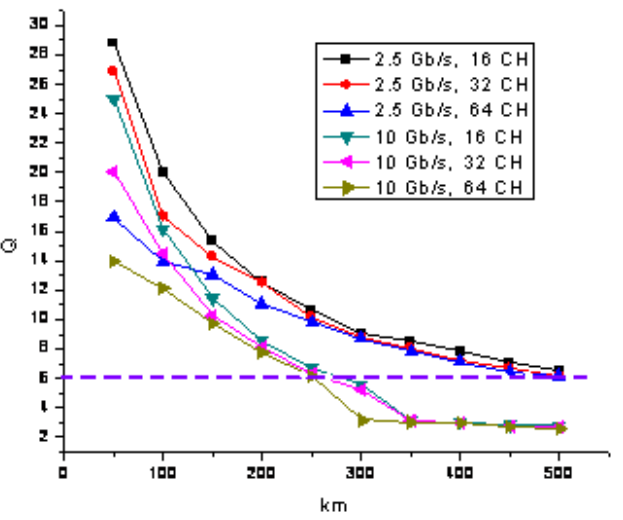

Fig. 4. Changing the $\mathrm{Q}$ factor for length of the amplifying section $50 \mathrm{~km}$. 


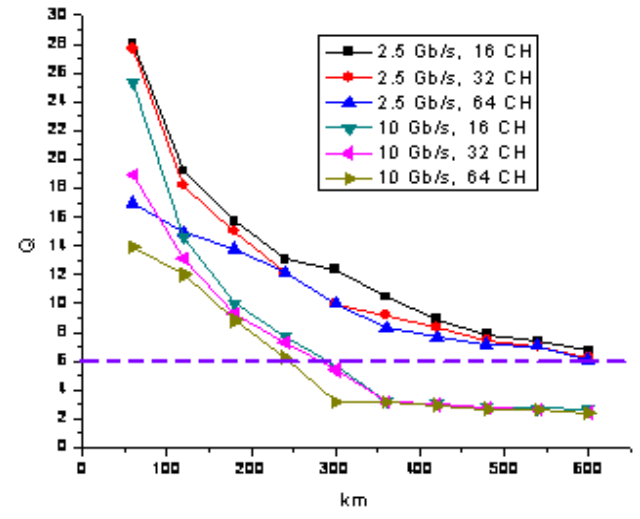

Fig. 5. Changing the $\mathrm{Q}$ factor for length of the amplifying section $60 \mathrm{~km}$.

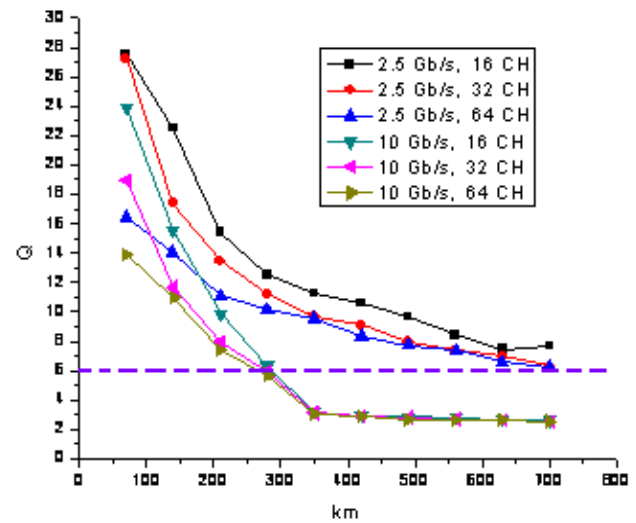

Fig. 6. Changing the $\mathrm{Q}$ factor for length of the amplifying section $70 \mathrm{~km}$.

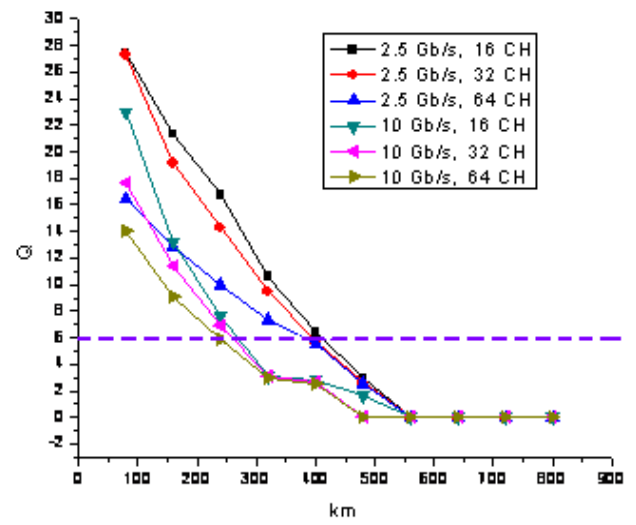

Fig. 7. Changing the $\mathrm{Q}$ factor for the length of the amplifying section $80 \mathrm{~km}$.

The given figures shows that with an increasing length of the amplifying section for the system of $10 \mathrm{~Gb} / \mathrm{s}$ there is no major change in quality with the larger length of signal transmission.

In the case of the system of $2.5 \mathrm{~Gb} / \mathrm{s}$, increasing the length of the amplifying sections means that there will be degradation of transmission quality.
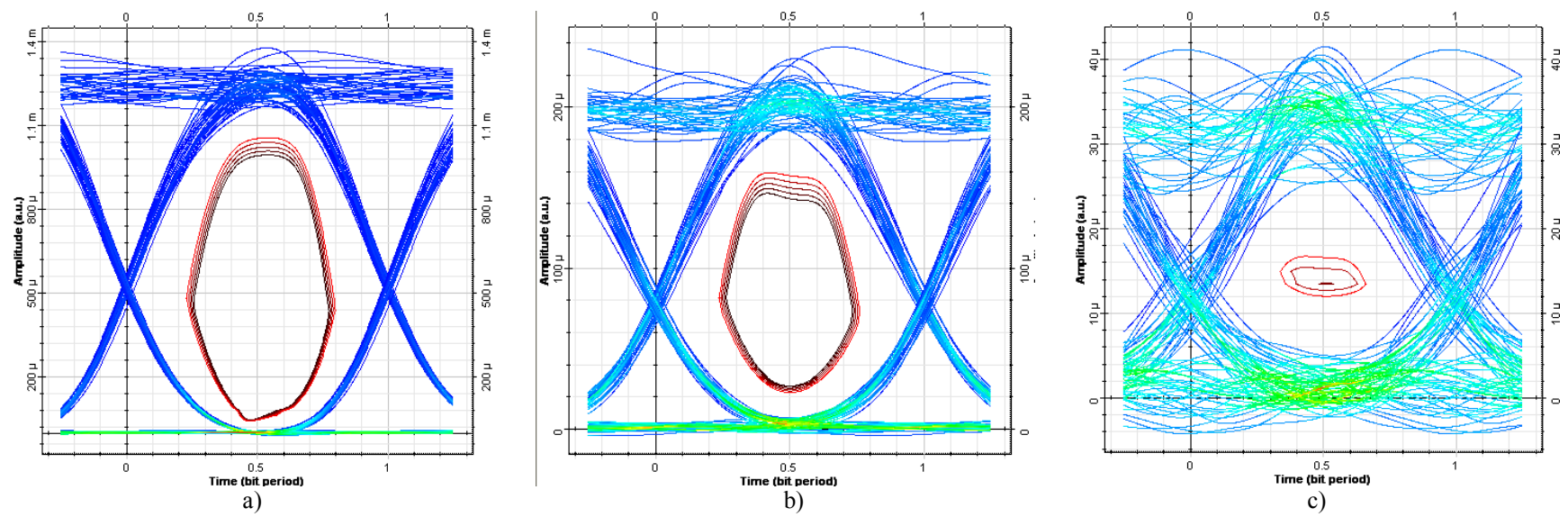

c)

Fig. 8. The eye diagram for flow rate per channel $2.5 \mathrm{~Gb} / \mathrm{s}$ and 16 DWDM channels: a) $80 \mathrm{~km}, \mathrm{~b}) 240 \mathrm{~km}$, c) $400 \mathrm{~km}$. 

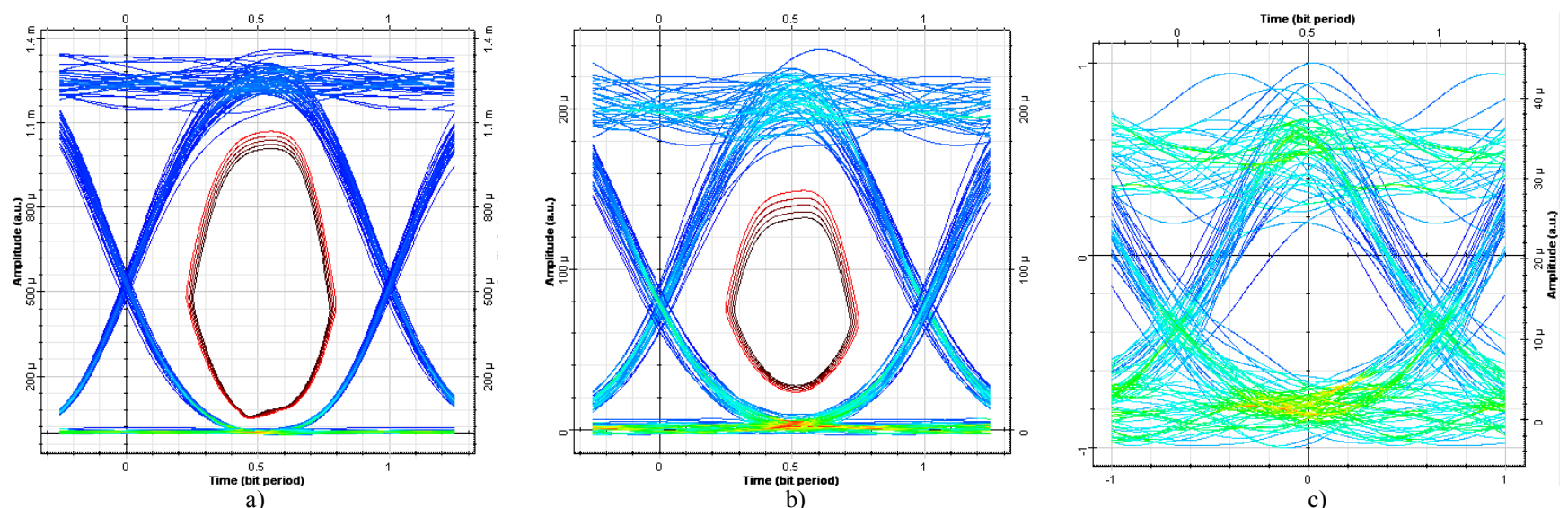

Fig. 9. The eye diagram for flow rate per channel $2.5 \mathrm{~Gb} / \mathrm{s}$ and 32 DWDM channels: a) $80 \mathrm{~km}, \mathrm{~b}) 240 \mathrm{~km}, \mathrm{c}) 400 \mathrm{~km}$.
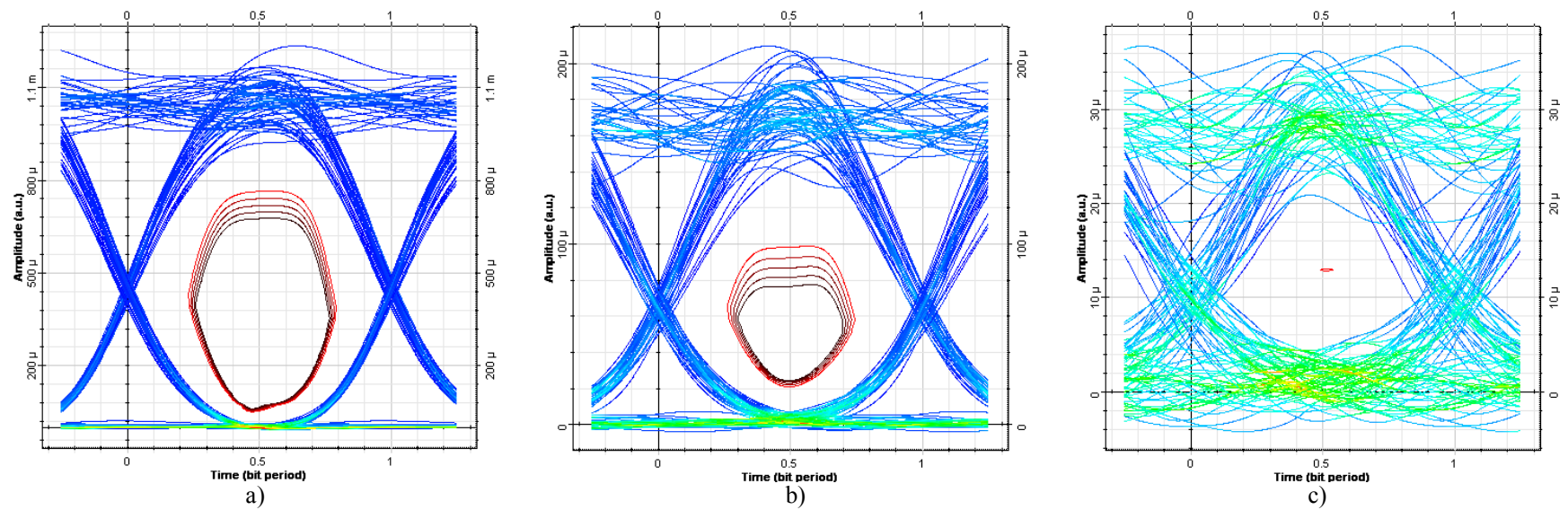

Fig. 10. The eye diagram for flow rate per channel $2.5 \mathrm{~Gb} / \mathrm{s}$ and 64 DWDM channels: a) $80 \mathrm{~km}, \mathrm{~b}) 240 \mathrm{~km}$, c) $400 \mathrm{~km}$.
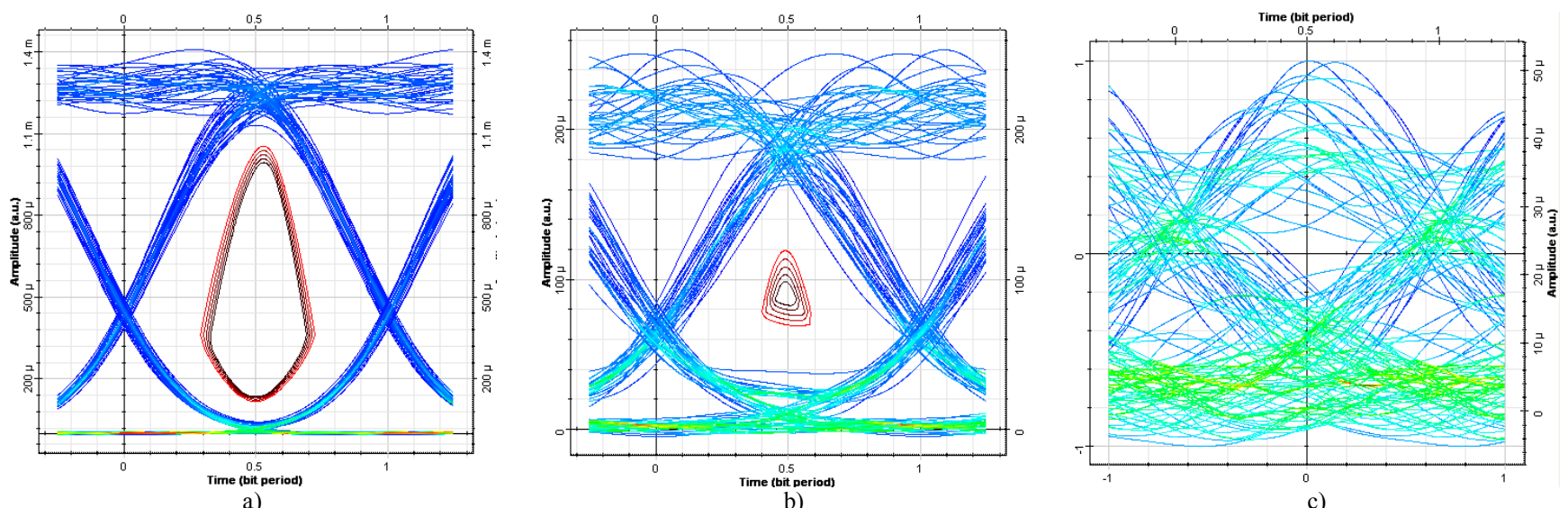

Fig. 11. The eye diagram for flow rate per channel $10 \mathrm{~Gb} / \mathrm{s}$ and 16 DWDM channels: a) $80 \mathrm{~km}, \mathrm{~b}) 240 \mathrm{~km}$, c) $400 \mathrm{~km}$. 

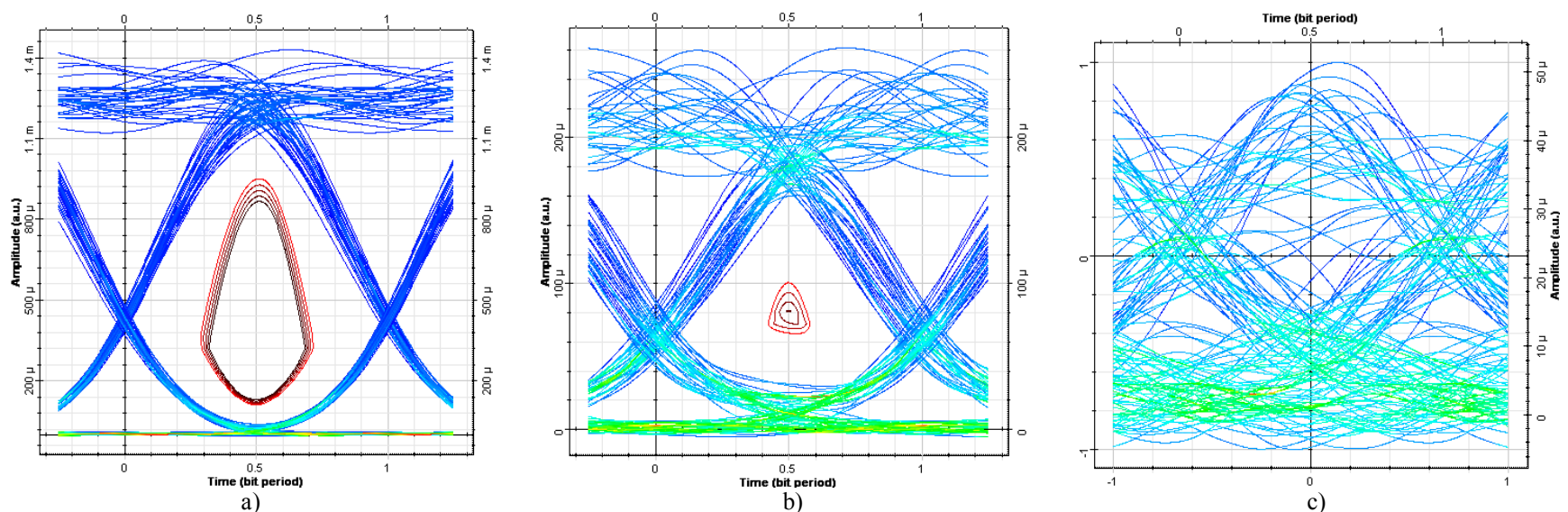

Fig. 12. The eye diagram for flow rate per channel $10 \mathrm{~Gb} / \mathrm{s}$ and 32 DWDM channels: a) $80 \mathrm{~km}$, b) $240 \mathrm{~km}$, c) $400 \mathrm{~km}$.

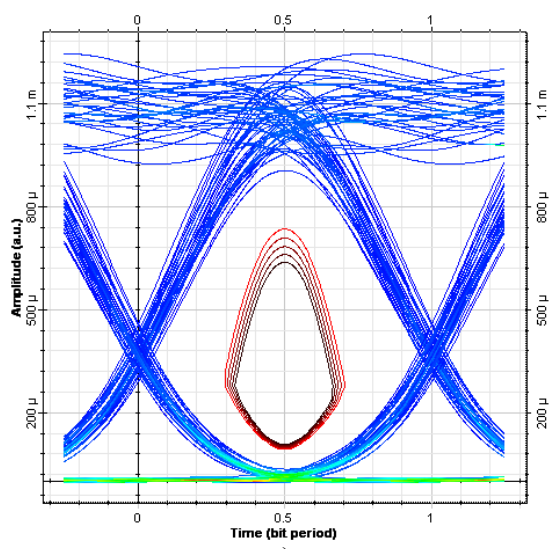

a)

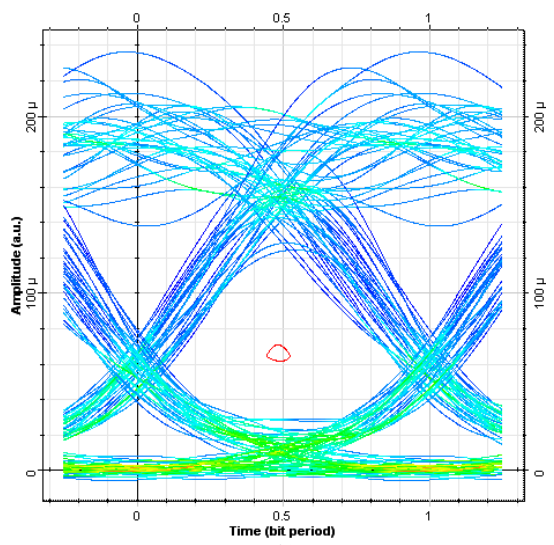

b)

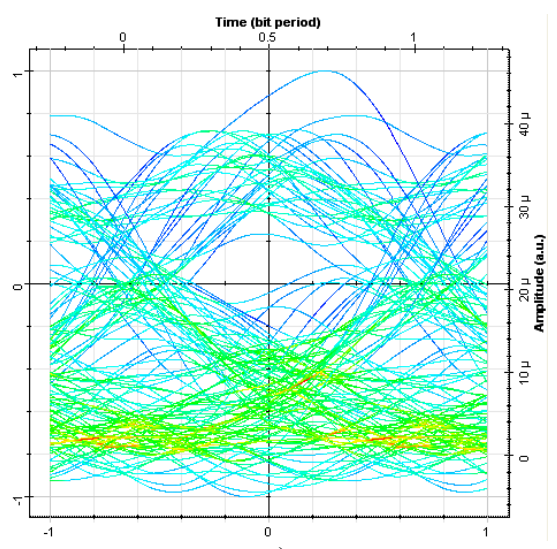

c)

Fig. 13. The eye diagram for flow rate per channel $10 \mathrm{~Gb} / \mathrm{s}$ and 64 DWDM channels: a) $80 \mathrm{~km}, \mathrm{~b}) 240 \mathrm{~km}, \mathrm{c}) 400 \mathrm{~km}$.

\section{CONCLUSION}

Based on a quality check algorithm, used for calculation of the distance at which the transmission quality is lost and for calculating the number of DWDM channels at which the optical signal will be distorted, simulations of the network for specific values are conducted. An analysis of the BER parameter and the $\mathrm{Q}$ factor shows that the length of the amplifying section, the flow rate per channel and the number of DWDM channels affect the transmission quality. Results showed that BER and Q are changing with the change in length of an amplifying section. Decrease of $Q$ is much more pronounced in the first amplifying section, while with the greater number of sections, it becomes approximately constant. A conclusion was made: with increasing length of the amplifying section for the system of $10 \mathrm{~Gb} / \mathrm{s}$ there is no major change in quality with the larger length of signal transmission. In the case of the system of $2.5 \mathrm{~Gb} / \mathrm{s}$, increasing the length of amplifying sections means that there will be degradation of transmission quality.

\section{ACKNOWLEDGMENT}

This work was done within the research project of the Ministry of Science and Technological Development of Serbia TR35026 and III47016.

\section{REFERENCES}

[1] K. M. Sivalingam, S. Subramaniam (Eds), Optical WDM Networks: Principles and Practice, Kluwer Academic, Norwell, MA, 2000

[2] M. T. Fatehi, M. Wilson, Optical Networking with WDM, McGraw-Hill, New York, 2001

[3] M. Stefanovic, D. Milic, “An approximation of filtered signal envelope with phase noise in coherent optical systems", Journal of Lightwave Technology, Vol .19, No. 11, pp. 1685-1690, 2001

[4] I. Djordjevic, M. Stefanovic, "Performance of optical heterodyne PSK systems with Costas loop in multichannel environment for nonlinear second-order PLL model", Journal of Lightwave Technology Vol. 17, No.12, pp. 2470-2479, 1999

[5] R. Ramaswami, K. Sivarajan, Optical Networks: A Practical Perspective, 2nd ed., Morgan Kaufmann Publishers, San Francisco, 2002

[6] I. P. Kaminow, T. Li, A. Willner (Eds), Optical Fiber Telecommunications V, Elsevier/Academic Press, 2008

[7] G. Agrawal, Nonlinear Fiber Optics, 2nd Ed., Academic Press, 2001

[8] G. Agrawal, Fiber-Optic Communication Systems, 3nd Ed., Wiley, 2002

[9] E. G. Sauter, Nonlinear Optics, John Wiley \& Sons, Inc., New York 
[10] M. Abramowitz, I. A. Stegun, Handbook of Mathematical Functions, Dover, New York, 1970

[11] Optiwave-Design Software for Photonics, OptiSystem-Optical Communication System and Amplifier Design Software, http://www.optiwave.com/products/system_overview.html (accessed 03.11 .2012 )

[12] International Telecommunication Union, "Optical fibers, cables and systems", ITU-T Manual, 2009

[13] International Telecommunication Union-ITU-T G.652, "Series G: Transmission systems and media, digital systems and networks. Transmission media and optical systems characteristics: Characteristics of a single-mode optical fibre and cable", ITU, 2009

\section{AUTHORS PROFILE}

Sinisa Ilic graduated at Faculty of Electrical Engineering in Pristina 1992 in the field of electronics and telecommunication. As B.Sc. engineer he worked at Television and Radio Pristina. He received his M.Sc. at Faculty of Electrical Engineering in Belgrade in the field of Digital Transmission of Information and defended $\mathrm{PhD}$ thesis at University of Pristina in the field of Digital Signal Processing and Computer Engineering. He is teaching now Databases, Design of Information Systems, Infrastructure of E-Commerce and Biomedical Informatics at Faculty of Technical Sciences in University of Pristina located in Kosovska Mitrovica. His areas of interest are: Databases,
Information Systems, Biomedical Informatics, Multimedia, Digital Signal Processing. He is author and co-author of many scientific papers published in journals and presented at international conferences. He is also involved in several educational projects and in several commercial projects related to introduction of Public Finance Management Information Systems.

Branimir Jaksic is assistant at the Department of Electronic and Computing Engineering, Faculty of Technical Sciences in Kosovska Mitrovica, Serbia. $\mathrm{He}$ is $\mathrm{PhD}$ candidate in the Faculty of Electronic Engineering, University of Nis, Serbia. Areas of research include optical and satellite communications. He has authored several scientific peer-reviewed papers on the above subject.

Mile Petrovic is full professor at the Department of Electronic and Computing Engineering, Faculty of Technical Sciences in Kosovska Mitrovica, Serbia. Areas of interest include telecommunications - television techniques. He has authored over 50 scientific peer-reviewed papers and a large number of projects and patents. He is a member of the technical program committee and reviewer for several international journals and symposia.

Aleksandar Markovic is $\mathrm{PhD}$ candidate in the Faculty of Electronic Engineering, University of Nis, Serbia. His research interests are statistical communication theory and optical communications. He has published several journal publications on the above subject.

Vanja Elcic is assistant at the University Slobomir P in Bijeljina, Bosnia and Herzegovina. His areas of interest include information technology and telecommunications. He has authored several scientific peer-reviewed papers in the field of information technology and telecommunication. 